\title{
Life Satisfaction during COVID-19
}

\author{
R. Deepa ${ }^{1^{*}}$ and A. Mansurali ${ }^{2}$ \\ PSG Institute of Management, Coimbatore 641 004, Tamilnadu, India \\ E-mail: ${ }^{1}<$ deepa@psgim.ac.in $>,{ }^{2}<$ mansurali@psgim.ac.in $>$
}

KEYWORDS Life Satisfaction. Marital Satisfaction. Mental Health. Pandemic. Physical Health

\begin{abstract}
As COVID-19 is still ravaging across the world, researchers are frantically examining the positive and negative impacts of the pandemic across the world. Amidst the encouraging signs of nature reclaiming itself, it would be interesting to estimate the levels of life satisfaction among the people. This descriptive study examined the life satisfaction of 275 respondents from Tamilnadu, the southernmost state of India. The respondents were selected using a multi-stage sampling technique. The study found that life satisfaction was highly prevalent amongst the respondents. COVID-19 had also brought families together and had confined people to the safety of their homes. The study also found that marital satisfaction, physical health and mental health were associated with life satisfaction. Physical health was found to be associated with social participation, mental health, and marital satisfaction implying that health is wealth. The study found no significant differences in life satisfaction across the demographic and socioeconomic factors.
\end{abstract}

\section{INTRODUCTION}

COVID-19 has left a trail of devastation across the world. Researchers are examining both the positive and negative effects of this pandemic on various aspects of our personal and professional lives. Krishnaveni and colleagues (2020), in their recent study had opined that COVID-19 had impacted the economic and social activities of people. Given this context, "How satisfied are people with their lives?” would be an interesting and difficult question to answer. Undoubtedly the answer to this question matters to people from all walks of life. Life satisfaction "is a judgmental process in which individuals assess their quality of life (QoL) in accordance with some unique set of criteria" (Banjare et al. 2015: 1). Life satisfaction is different from happiness. Happiness is an emotional or experiential evaluation of subjective well-being whereas life satisfaction is a cognitive or rational assessment of one's subjective wellbeing (Ngoo et al. 2015). Several studies have claimed that age, gender, economic status, education, marital status, income level and the role of government are some of the determinants of life

*Address for correspondence:

Dr. R. Deepa

Associate Professor,

PSG Institute of Management,

PB \# 1668, Avinashi Road,

Peelamedu, Coimbatore 641004,

Tamilnadu, India

Phone: 91-422-4304400,

E-mail:deepa@psgim.ac.in satisfaction. According to the World Happiness Report (Ortiz-Ospina and Roser 2020), the selfreported life satisfaction of Indians had steadily declined between 2016 and 2018 (2016 - 4.18; 2017 - 4.05; 2018 - 3.82 on a 10 point ranking). The report also states that richer countries tend to have a high self-reported life satisfaction than poorer countries and that there is a correlation between GDP per capita and self-reported life satisfaction. Income, economic growth, health, life expectancy, disability, sense of freedom, culture, and society are other factors that had influenced life satisfaction, across 160 countries examined (Ortiz-Ospina and Roser 2020).

Ngoo and colleagues (2015) have reported that there is a lacuna in terms of the number of studies on life satisfaction and happiness across Asia. They had found only a few studies in China and other Asian countries. In India, a few studies have examined the life satisfaction of elderly people. It was found that elderly people reported a low level of life satisfaction (Maheswaran and Ranjith 2013). A study on elderly people in Kerala found no significant differences in life satisfaction between elderly men and women (Balachandran et al. 2007). Marpady et al. (2012) examined the life satisfaction of elderly in rural Karnataka and found that family support is a significant factor for the life satisfaction and psychological wellbeing of the elderly. Ortiz-Ospina and Roser (2020) report that life events can significantly impact the life satisfaction of individuals. Given the dearth of studies on life satisfaction in the Asian context and the prevailing context of COVID-19, 
the study aims to examine the life satisfaction of individuals across different walks of life in Tamilnadu, the southern-most state of India.

\section{Literature Review}

Life satisfaction (LS) has been defined in many ways. LS is not the same as happiness. Happiness is the experiential evaluation of subjective well-being, whereas LS is the cognitive evaluation of subjective well-being. According to Ellison and colleagues (1989), LS is “a cognitive assessment of an underlying state thought to be relatively consistent and influenced by social factors". Veenhoven (1996) opines that LS is the degree to which individuals like the life they lead. Ackerman (2020) states that LS is broader in scope and is based on the rational judgment by individuals, about the factors that they consider to be the most important for them. She also states that LS is influenced by factors from different facets of life namely work, marital relationships, relationships with friends and family, personal development, health, wellness etc. A review of research revealed that LS is influenced by many demographic and socio-economic factors like age, gender, education, marital status, income, economic status etc.

\section{Age}

Age is said to have a ' $U$ ' shaped relationship with LS. The younger and older people report a high LS compared to the middle aged people (Blanchflower and Oswald 2004; Peiro 2006; Blanchflower 2008; Dolan et al. 2008). As people grow old, they gain a lot of experience managing their life and learn to adapt to life, resulting in a sense of satisfaction with life (Sotgiu et al. 2011). Age had a significant impact on the LS of females, compared to males (Ferring et al. 2004). However, a few studies reported that age was not positively associated with LS (Delhey 2004; Subasi and Hayran 2005). Ngoo and colleagues, (2015) also found that in South Asia, age did not predict LS. In a latest study (Bartram 2020) it is argued that the U-shaped relationship between age and life satisfaction cannot exist.

\section{Gender}

The impact of gender on LS varies across countries. However the differences were found to be generally insignificant (Ngoo et al. 2015). Women were more satisfied with their life than men in the United States of America, while men had a higher LS compared to women in Russia (Dolan et al. 2008). According to a few studies, gender was not positively associated with LS (Delhey 2004; Subasi and Hayran 2005). Balachandran et al. (2007) found no significant differences in LS among elderly men and women from Kerala, South India.

\section{Education}

Studies from the past (Ozer and Sackes 2011; Chen 2012; Cunado and de Gracia 2012) found that as the level of education increases, people are more equipped to realize their goals, they tend to have an optimistic and realistic orientation towards life and hence LS increases. Salinas-Jimenez and colleagues (2011) found that education has a significant and positive impact on LS. However, Schimmel (2009) opines that increase in education level should be supported by opportunities to earn a higher income, which again is a predictor of LS. According to Binder and Coad (2011), the impact of education on LS is only until a certain level. A few studies, mostly on elderly people done in different contexts (Fernandez-Ballesteros et al. 2001; Sener et al. 2008; Suh et al. 2012; Ra et al. 2013) have also found a moderate influence of education on LS. In a study on South Asian respondents, Ngoo and colleagues, (2015) found that people with a higher level of education were less satisfied with their life compared to people with a middle level education. They also found that education did not have any association with LS in central and west Asia and that there was a moderate association between education and LS in southeast Asia.

\section{Income and Economic Status}

A high level of income was found to have a positive impact on LS (Appleton and Song 2008; Ball and Chernova 2008; Dolan et al. 2008). A few studies (Møller 2007; Mahadea and Rawat 2008; Posel and Casale 2011) in the South African context have revealed a positive association between income and LS. According to Haggerty and Veenhoven (2003) the positive impact of income on LS is significant only for a short term but not for a 
long term. Easterlin (1995) opined that the effect of income on LS may not be the same for all individuals. Income has a significant impact on the LS of poor people compared to that of rich people (Helliwell et al. 2011). Daraei and Mohajery (2013) found a positive correlation between socioeconomic status and LS. In a study on Turkish adolescents, Eroglu and colleagues, (2009) found that the LS of students varied across socioeconomic status. A study conducted in South Africa (Yul and Gaibie 2011) revealed that people in high income bracket report high LS than those in the low income bracket. Nettle (2005) has opined that the effect of income or economic status on LS of people is unclear. Easterlin (2003) has opined that as income of people increases, their material needs also increase leading to no improvement in LS. According to Myers and Diener (1996), though the income levels of developed countries had increased, there is no subsequent increase in the well-being or LS of people. Thus the reviews related to the association between income, economic status and LS are mixed.

\section{Marital Status and Marital Satisfaction}

A few studies found that the life satisfaction of married people was higher than that of unmarried, separated or divorced people (Clark and Oswald 1999; Peiro 2006; Dolan et al. 2008). Gove and colleagues (1983) also opine that married people are highly satisfied with their life. According to Frazier et al. (1996), married men reported higher life satisfaction compared to married women. Ngoo and colleagues (2015) also found that life satisfaction was high among married people. A few studies (Schoenborn 2004; Bennett 2005) revealed that respondents who were in formal marriages had a high level of life satisfaction. A study conducted on Canadian respondents (Hoskins and May 2016) found that marital status is a significant predictor of LS. In a study conducted on South African adults, Botha and Booysen (2013) found that marital satisfaction is positively associated with LS only among women and not among men. Kasapoglu and Yabanigul (2018) found that marital satisfaction was a significant predictor of LS among married individuals in Istanbul, Turkey.

\section{Self-rated Mental and Physical Health}

Several studies have shown that self-reported health is a predictor of LS (O’Neill 2010). Health is considered to be an important factor which could account for LS (Kim and Shin 2009; Tiliouine 2009; Veenhoven 2009). According to Gwozdz and Sousa-Poza (2010), ill health was negatively associated with LS. Several other studies (Oshio and Kobayashi 2010; Kim 2012; Lee and Oh 2013; Mafini 2017) have also revealed the significant and positive association between health and LS. The LS of respondents who reported good health was five times more than the LS of respondents who reported poor health (Vinson and Ericson 2012). In a study in South Africa (Ebrahim et al. 2013) health emerged as a significant predictor of LS among all racial groups. Prince and Colleagues (2007) stated that mental health is an integral part of health. In a study done at Canada, Lombardo et al. (2018) found a significant association between self-reported mental health and LS. Hoskins and May (2016) also found that self-rated health was a significant predictor of LS.

\section{Social Participation}

Family and social activities are important aspect of an individual's life. Iwatsuba et al. (1996) found that leisurely activities (spending time with family, indulging in hobbies etc.) predicted the LS of retired people in Paris. Based on substantial evidence from literature, Amati et al. (2018) stated that individuals with active social relationships would be more satisfied with their lives. These relationships satisfy the social needs of individuals (Deci and Ryan 2002) and make them satisfied. If individuals have more people around them to trust and to share their problems and important matters, their well-being is enhanced, leading to LS (Taylor et al. 2001; Powdthavee 2008). Sound relationships also have an impact on health and LS (Nguyen et al. 2015). During risky times, social interactions can protect and support individuals and equip them with coping skills, resulting in LS (Myers 2000; Halpern 2005).

The review of literature revealed the associations between age, gender, education, economic status, marital status, marital satisfaction, selfreported health and social participation. After examining the associations between the different factors, the study arrived at the following framework (See Fig. 1). Based on the framework, and in the context of COVID-19, the study aims to ad-

J Hum Ecol, 71(1-3): 127-138 (2020) 


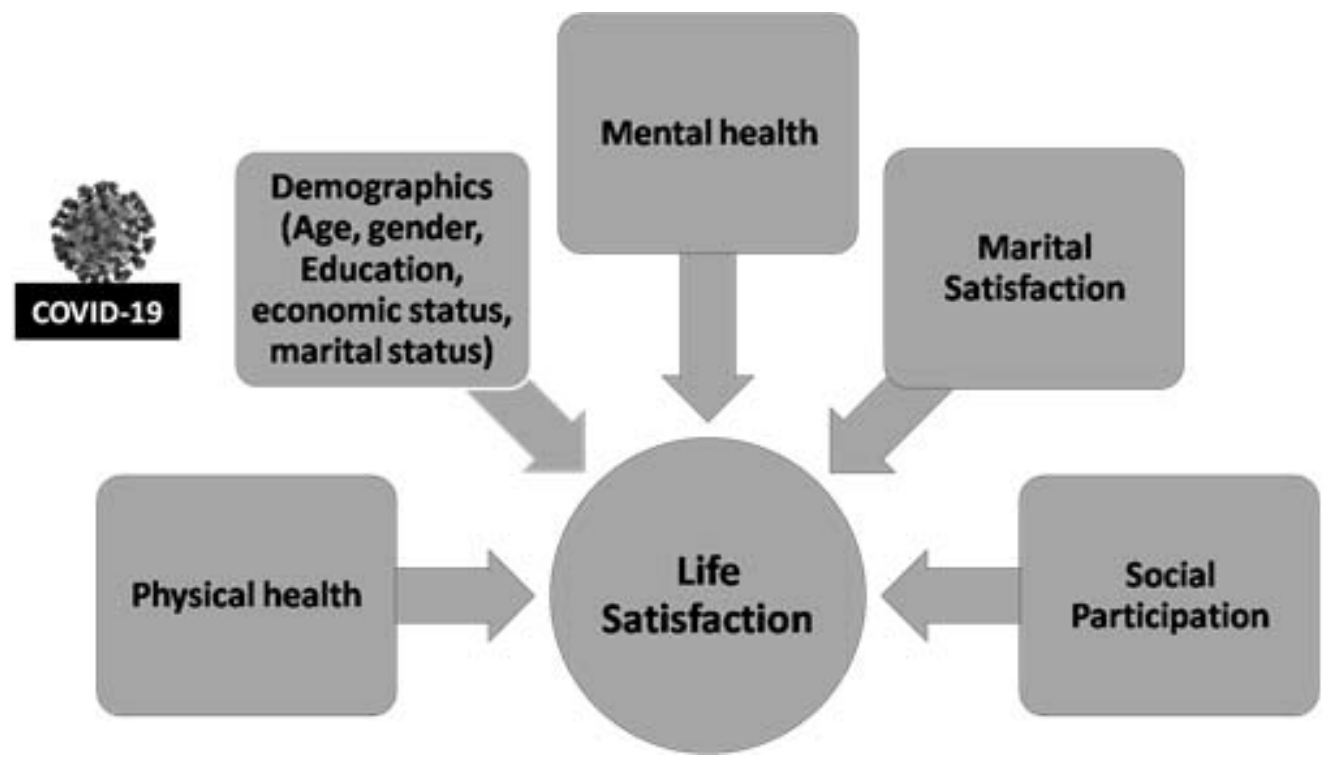

Fig. 1. Theoretical framework for the study Source: Authors

dress the lacuna in research related to LS in Asian countries and attempts to answer the following questions:

\section{Research Questions}

1. How satisfied were people with their life during COVID-19?

2. Does life satisfaction vary across age, gender, education, marital status and economic status?

3. What are the determinants of life satisfaction?

4. What is the effect of COVID-19 on the life satisfaction of people?

\section{METHODOLOGY}

The study was descriptive and was conducted in Tamilnadu, the southernmost state of India. The respondents were from all walks of life. The sample for the study was arrived as below:

\section{Sample}

The sample for the study was selected in two stages. In the first stage, the questionnaire was shared among the personal and professional contacts of the authors, with a request to respond. In the second stage, the contact members of the authors were also requested to share it among their contacts. This yielded a sample of 300 respondents from all walks of life. Out of 300 responses, only 276 were complete and were considered for the study. The demographics of the respondents is presented in Table 1.

\section{Measures Used}

Life satisfaction was measured by the Riverside Life Satisfaction Scale (Margolis et al. 2019). The life satisfaction scale has 6 items on a fivepoint scale. The total score for the 6 items is calculated and interpreted as 5 levels of LS namely 6 - 11 extremely dissatisfied; 12 - 17 dissatisfied; 18 - neutral, 19 - 24 satisfied; and 25 - 30 extremely satisfied. Marital satisfaction was measured using a Likert scale by Hendrick (1988). The other independent variables like self-reported health and social participation were measured using Likert scales. The measures were integrated into one questionnaire with provisions to capture the demographics and sent as Google forms to the respondents. 
Table 1: Demographics of the respondents

\begin{tabular}{|c|c|c|}
\hline & $N$ & $\%$ \\
\hline \multicolumn{3}{|l|}{1 Gender } \\
\hline Male & 164 & 59.6 \\
\hline Female & 111 & 40.36 \\
\hline Total & 275 & 100 \\
\hline \multicolumn{3}{|l|}{ 2. Relationship Status } \\
\hline Single & 110 & 40 \\
\hline Married & 164 & 59.64 \\
\hline Divorced & 1 & 0.36 \\
\hline Total & 275 & 100 \\
\hline \multicolumn{3}{|c|}{3 Received Salary during } \\
\hline \multicolumn{3}{|c|}{ Lock down } \\
\hline Yes & 187 & 68 \\
\hline No & 88 & 32 \\
\hline Total & 275 & 100 \\
\hline \multicolumn{3}{|l|}{ 4. Connect with family } \\
\hline Away from family & 48 & 17.45 \\
\hline With family & 227 & 82.55 \\
\hline Total & 275 & 100 \\
\hline \multicolumn{3}{|l|}{5 Economic status } \\
\hline Lower middle class & 6 & 2.18 \\
\hline Middle class & 145 & 52.73 \\
\hline Upper middle class & 117 & 42.55 \\
\hline Upper class & 7 & 2.55 \\
\hline Total & 275 & 100 \\
\hline \multicolumn{3}{|l|}{ 6. Corona Zone } \\
\hline Green & 34 & 12.36 \\
\hline Orange & 55 & 20 \\
\hline Red & 186 & 67.64 \\
\hline Total & 275 & 100 \\
\hline \multicolumn{3}{|l|}{7 Lockdown job status } \\
\hline Not working & 91 & 33.09 \\
\hline Work at office & 30 & 10.91 \\
\hline Work from home & 154 & 56 \\
\hline Total & 275 & 100 \\
\hline \multicolumn{3}{|l|}{8 Age } \\
\hline $18-25$ & 81 & 29.4 \\
\hline $26-35$ & 87 & 31.6 \\
\hline $36-45$ & 51 & 18.55 \\
\hline $46-55$ & 35 & 12.73 \\
\hline Above 55 & 21 & 7.64 \\
\hline Total & 275 & 100 \\
\hline \multicolumn{3}{|l|}{9 Education } \\
\hline SSLC & 3 & 1.09 \\
\hline Diploma & 4 & 1.45 \\
\hline UG & 56 & 20.36 \\
\hline PG & 186 & 67.64 \\
\hline $\mathrm{PhD}$ & 26 & 9.45 \\
\hline Total & 275 & 100 \\
\hline \multicolumn{3}{|l|}{ 10. Employment Status } \\
\hline Unemployed & 40 & 14.55 \\
\hline Home maker & 19 & 6.9 \\
\hline Employed & 173 & 62.9 \\
\hline Self-employed & 43 & 15.64 \\
\hline Total & 275 & 100 \\
\hline
\end{tabular}

\section{DISCUSSION}

SPSS was used to analyze the data and the results are presented below

\section{Prevalent Levels of LS}

The total score obtained by the respondents using the Riverside Life Satisfaction Scale is divided into 5 levels, extremely dissatisfied, dissatisfied, neutral, satisfied and extremely satisfied. The LS levels of the 275 respondents is presented in Table 2.

Table 2: Prevalence of life satisfaction

\begin{tabular}{lc}
\hline Life Satisfaction Levels & Percent \\
\hline Extremely dissatisfied & 4 \\
Dissatisfied & 16.3 \\
Neutral & 10.2 \\
Satisfied & 59.3 \\
Extremely satisfied & 10.2 \\
\hline Total & 100.0 \\
\hline
\end{tabular}

The study found that 70 percent of the respondents are satisfied with their lives, even in the context of COVID-19. Around 10 percent have responded to be neutral with LS. There are 20 percent respondents who are not satisfied with their lives. The mean value of LS is 3.56, which shows that on an average the respondents were satisfied with their lives. According to Bilal and Rasool (2020), life satisfaction is an indicator of general well-being, psychological well-being and happiness. Hence, the highly prevalent levels of life satisfaction is a welcome and encouraging sign. When individuals are with family and with more people around them, there are bright chances for exchange of feelings and ideas, leading to LS (Taylor et al. 2001; Powdthavee 2008). The highly prevalent LS among respondents could be explained because 82 percent of the respondents where with their family during COVID-19. Family support was found to be an important determinant of life satisfaction among Brazilian college students (Vautero et al. 2020). Hence the fact that most of the respondents were with their families might have contributed to the enhanced life satisfaction levels, despite the pandemic lurking around. Ortiz-Ospina and Roser (2020) had opined that the LS of Indians had been steadily declining since 2015. However, this study gives a fresh breather by revealing that 70 percent of respondents are satisfied with their life. The demographic details of the respondents as seen in Table 1 show that 67 percent of the respondents

J Hum Ecol, 71(1-3): 127-138 (2020) 
were from the red zone, where the infection was at its highest. In these areas, people had strict restrictions and most of them had to work from home. It is also evident that 83 percent of the respondents were connected with family and 68 percent of them had received their salary. Though the danger of COVID-19 was existent, most of them had their salaries at home, they were confined to the safely of their homes and above all most of them were connected with family. Given these facts, it is fair enough to assume that the respondents were comfortable and satisfied with their life.

\section{LS Across Demographic and Socioeconomic Characteristics of Respondents}

The levels of LS across the different characteristics of respondents is shown in Table 3.
Though the numbers seem different across groups, the statistical significance is to be tested.

After ensuring the prerequisites for Chisquare (categorical variables, assumption of independence) and ANOVA (outliers, normality of data points), statistical tests were performed to examine the association between LS and demographics like age, gender, education, economic status, employment status, and marital status. The statistical tests did not reveal any significant difference in the LS levels across demographics.

In a study conducted across the Asian continent, Ngoo and colleagues (2015) found that age and gender did not emerge as significant predictors of LS for respondents from South Asia. India rightly fits into South Asian context and hence there is a replication of the outcome of a study in the recent past. Age and gender were not found to be associated with LS in a few previous studies (Delhey 2004; Subasi and Hayran 2005). Bal-

Table 3: Life satisfaction across demographics

\begin{tabular}{|c|c|c|c|c|c|c|c|c|c|c|c|}
\hline \multirow[t]{2}{*}{ Demography } & \multicolumn{2}{|c|}{$\begin{array}{l}\text { Extremely } \\
\text { dissatisfied }\end{array}$} & \multicolumn{2}{|c|}{ Dissatisfied } & \multicolumn{2}{|c|}{ Neutral } & \multicolumn{2}{|c|}{ Satisfied } & \multicolumn{2}{|c|}{$\begin{array}{l}\text { Extremely } \\
\text { satisfied }\end{array}$} & \multirow{2}{*}{$\begin{array}{l}\text { Total } \\
\qquad N\end{array}$} \\
\hline & $N$ & $\%$ & $N$ & $\%$ & $N$ & $\%$ & $N$ & $\%$ & $N$ & $\%$ & \\
\hline \multicolumn{12}{|l|}{ Gender } \\
\hline Male & 4 & 2.4 & 28 & 17.1 & 19 & 11.6 & 92 & 56.1 & 21 & 12.8 & 164 \\
\hline Female & 6 & 5.4 & 17 & 15.3 & 9 & 8.1 & 72 & 64.9 & 7 & 6.3 & 111 \\
\hline \multicolumn{12}{|l|}{ Age } \\
\hline $18-25$ & 5 & 6.2 & 13 & 16 & 10 & 12.3 & 46 & 56.8 & 7 & 8.6 & 81 \\
\hline $26-35$ & 3 & 3.4 & 11 & 12.6 & 12 & 13.8 & 56 & 64.4 & 5 & 5.7 & 87 \\
\hline $36-45$ & 0 & 0 & 9 & 17.6 & 3 & 5.9 & 30 & 58.8 & 9 & 17.6 & 51 \\
\hline $46-55$ & 2 & 5.7 & 9 & 25.7 & 3 & 8.6 & 17 & 48.6 & 4 & 11.4 & 35 \\
\hline Above 55 & 0 & 0 & 3 & 14.3 & 0 & 0 & 15 & 71.4 & 3 & 14.3 & 21 \\
\hline \multicolumn{12}{|c|}{ Relationship Status } \\
\hline Single & 6 & 5.5 & 19 & 17.3 & 15 & 13.6 & 63 & 57.3 & 7 & 6.4 & 110 \\
\hline Married & 4 & 2.4 & 26 & 15.9 & 13 & 7.9 & 100 & 61 & 21 & 12.8 & 164 \\
\hline Divorced & 0 & 0 & 0 & 0 & 0 & 0 & 1 & 0.4 & 0 & 0 & 1 \\
\hline \multicolumn{12}{|l|}{ Education } \\
\hline SSLC & 0 & 0 & 0 & 0 & 0 & 0 & 0 & 0 & 3 & 100 & 3 \\
\hline Diploma & 0 & 0 & 0 & 0 & 0 & 0 & 2 & 50 & 2 & 50 & 4 \\
\hline UG & 2 & 3.6 & 13 & 23.2 & 4 & 7.14 & 31 & 55.5 & 6 & 10.7 & 56 \\
\hline PG & 6 & 3.2 & 32 & 17.2 & 21 & 11.3 & 117 & 62.9 & 10 & 5.4 & 186 \\
\hline $\mathrm{PhD}$ & 2 & 8 & 0 & 0 & 3 & 12 & 13 & 12 & 7 & 28 & 26 \\
\hline \multicolumn{12}{|c|}{ Employment Status } \\
\hline Unemployed & 1 & 2.5 & 3 & 7.5 & 8 & 20 & 24 & 60 & 4 & 10 & 40 \\
\hline Home Maker & 0 & 0 & 5 & 26.3 & 1 & 5.3 & 13 & 68.4 & 0 & 0 & 19 \\
\hline Employed & 6 & 3.5 & 24 & 14 & 16 & 9.3 & 104 & 61 & 22 & 12.8 & 172 \\
\hline Self-employed & 3 & 7 & 13 & 30 & 3 & 7 & 22 & 51.2 & 2 & 4.7 & 43 \\
\hline \multicolumn{12}{|l|}{ Economic Status } \\
\hline L. Middle class & 0 & 0 & 1 & 16.7 & 1 & 16.7 & 3 & 50 & 1 & 16.7 & 6 \\
\hline Middle class & 5 & 3.4 & 25 & 17.2 & 16 & 11.0 & 85 & 58.6 & 14 & 9.7 & 145 \\
\hline U. Middle class & 5 & 4.3 & 13 & 11.2 & 11 & 9.5 & 75 & 64.7 & 12 & 10.3 & 116 \\
\hline Upper class & 0 & 0 & 6 & 85.7 & 0 & 0 & 0 & 0 & 1 & 14.3 & 7 \\
\hline
\end{tabular}

J Hum Ecol, 71(1-3): 127-138 (2020) 
achandran and colleagues, (2007) conducted a study among elderly men and women in Kerala, another state South India and found no difference in LS among men and women. Thus the outcome of this study stands justified.

From previous research studies, it is evident that there was a mixed outcome with respect to the association between education and LS. While a few studies done on elderly people in different contexts (Fernandez-Ballesteros et al. 2001; Sener et al. 2008; Suh et al. 2012; Ra et al. 2013) found a moderate positive association between education and LS, a study conducted in Asia found no significant association between education and LS among respondents from Central and West Asia. The absence of association between LS and education is thus explained.

The study (Ngoo et al. 2015) also found that the LS of employed people is low compared to that of unemployed people. This study contradicts these previous outcomes and finds no difference in LS between employed and unemployed people. Though statistically insignificant, it can be seen from Table 3 that more number of selfemployed people (37\%) were dissatisfied with their lives, compared to unemployed (10\%), employed (17\%) and home makers (26\%). During COVID19 , the businesses were shut down and hence self-employed people might have become anxious about the future of their businesses. This might have contributed to their dissatisfaction.

A few studies (Møller 2007; Mahadea and Rawat 2008; Posel and Casale 2011) in the South African context had reported a positive association between economic status and LS. A positive correlation was reported between socioeconomic status and LS from different contexts across the world (Eroglu et al. 2009; Daraei and Mohajery 2013). Yul and Gaibie (2011) found that people with high income report high LS. However, this study found no association between economic status and LS. As the income level of people increases, their material needs also increase, nullifying the effect of high income (Easterlin 1995). Myers and Diener (1996) reported no increase in the LS of people in developed countries despite increase in income levels. Thus the absence of association between economic status and LS stands justified.

Married people were found to report high levels of LS compared to single and divorced people
(Gove et al. 1983; Clark and Oswald 1999; Peiro 2006; Dolan et al. 2008). In a study done in the Asian context, Ngoo and colleagues (2015) found married people to be highly satisfied with life compared to unmarried people. Hoskins and May (2016) also found marital status to be significant predictor of LS. Contradicting all these similar findings from the past, this study done in the context of COVID-19 found no difference in LS between married and unmarried people. Further deep analysis and examination is required to attribute this contradicting result to COVID-19.

\section{Interplay between LS and Its Antecedents}

From the review, it was evident that apart from the demographic factors, mental health, physical health, marital satisfaction and social participation could also influence LS. Given the context of COVID-19, a bivariate correlation was performed to test if the framework holds good in the South Indian context. It is to be noted that a correlation can be used only to examine the associations between dependent and independent variables (De Vaus 2001; Sukamolson 2007).

After ensuring the prerequisites to perform a correlation, a bivariate correlation was performed between LS and its antecedents. The results are presented in Table 4.

It is evident from Table 4 that marital satisfaction, physical health and mental health are associated with LS. While physical and mental health are weakly associated with LS, marital satisfaction is moderately associated with LS. A study conducted in Istanbul, Turkey (Kasapoglu and Yabanigul 2018) found marital satisfaction be a significant predictor of LS among married individuals. However, Botha and Booysen (2013) found that marital satisfaction predicted LS only among women. In this study, despite the presence of 110 respondents with 'single' status, marital satisfaction was found to be moderately associated with LS, in line with the previous research studies. In a study done in Tamilnadu during the pandemic, Mansurali and colleagues, (2020) found that 73 percent of the respondents were satisfied with their marital relationships. As this study was also done in the same region, the highly prevalent levels of marital satisfaction as found out by Mansurali and colleagues (2020) might explain the fact that around 70 percent of

J Hum Ecol, 71(1-3): 127-138 (2020) 
Table 4: Results of bivariate correlation between life satisfaction and its antecedents

\begin{tabular}{|c|c|c|c|c|c|c|}
\hline & & $P H$ & $S P$ & MS & $M H$ & $L S$ \\
\hline \multirow[t]{3}{*}{$P H$} & Pearson Correlation & 1 & $0.31^{* *}$ & $0.20^{* *}$ & $0.46^{* *}$ & $0.13^{* *}$ \\
\hline & Sig. (2-tailed) & & 0 & 0.001 & 0 & 0.033 \\
\hline & $\mathrm{N}$ & & 275 & 275 & 275 & 275 \\
\hline \multirow[t]{3}{*}{$S P$} & Pearson Correlation & & 1 & -0.11 & $0.29^{* *}$ & 0.03 \\
\hline & Sig. (2-tailed) & & & 0.067 & 0 & 0.599 \\
\hline & $\mathrm{N}$ & & & 275 & 275 & 275 \\
\hline \multirow[t]{3}{*}{$M S$} & Pearson Correlation & & & 1 & 0.04 & $0.27^{* *}$ \\
\hline & Sig. (2-tailed) & & & & 0.467 & 0 \\
\hline & $\mathrm{N}$ & & & & 275 & 275 \\
\hline \multirow[t]{3}{*}{$M H$} & Pearson Correlation & & & & 1 & $0.16^{* *}$ \\
\hline & Sig. (2-tailed) & & & & & 0.008 \\
\hline & $\mathrm{N}$ & & & & & 275 \\
\hline \multirow[t]{3}{*}{$L S$} & Pearson Correlation & & & & & 1 \\
\hline & Sig. (2-tailed) & & & & & \\
\hline & $\mathrm{N}$ & & & & & \\
\hline
\end{tabular}

${ }^{* *}$ p $<0.01 ;$ PH = Physical Health; SP = Social Participation; MS = Marital Satisfaction; MH = Mental Health; LS = Life Satisfaction

the respondents in this study were satisfied with their life, despite the presence of 110 unmarried people.

A few studies (Kim and Shin 2009; Tiliouine 2009; Veenhoven 2009; Hoskins and May 2016) had found that self-reported health is an important factor that could predict LS. There was a significant positive association between self-reported health and LS (Osho and Kobayashi 2010; Kim 2012; Lee and Oh 2013; Mafini 2017). In a study done on older adults in Columbia (Reyes et al. 2019), LS correlated positively with psychological well-being. Self-reported mental health was also found to be associated with LS (Lombardo et al. 2018). The present study has strengthened the previous findings by revealing the statistically significant association between health (both physical and mental) and LS. Physical health was found to be associated with mental health, social participation, marital satisfaction and life satisfaction, showing the profound importance of health in our lives.

Social participation was identified as a predictor of LS by a few studies (Iwatsuba et al. 1996; Amati et al. 2018). A few studies found that when individuals have more people around them, then mutual sharing of issues and feelings is facilitated leading to LS. However, in this study social participation was not found to be associated with LS.

The study came out with a positive outcome that seventy percent of the respondents are satis- fied with their lives. Life satisfaction is associated with physical health, mental health and marital satisfaction according to previous studies and also as per this study. It can be understood from the outcome of this study that people are satisfied with their relationships and life. According to Hofstede's cultural dimensions, India is high in collectivism and low to medium in Uncertainty avoidance. In a collectivistic culture, relationships between individuals are given more importance. It is a family-oriented culture. In a low uncertainty avoidance culture, people are more patient and show more tolerance towards unexpected events. They seek change instead of avoiding it (Cayla. Weebly.com 2020). Due to these deep rooted cultural dimensions, the respondents would have developed patience and tolerance towards the pandemic and would have adapted to it, thereby leading to life satisfaction.

The literature review showed mixed outcomes for all of the demographics except marital status. However, in this study, there were no differences in LS across the demographic and socioeconomic groups. There were certain COVID-19 induced conditions among the respondents like their working status during lock down, the COVID-19 zone they lived in etc. It would be interesting to examine if these induced conditions had an association with LS. The COVID-19 specific analysis follows. 


\section{Effect of COVID-19 on LS}

During the study, the entire nation was on lockdown. The respondents were from three different zones namely red, orange and green in the order of decreasing intensity of the infection. The levels of LS across the corona zones, lockdown status and connect with family were examined. There was no significant difference in the LS of respondents, across corona zones, lockdown job status and connect with family as shown in Table 5.

Table 5: Life satisfaction across Corona specific characteristics - ANOVA results

\begin{tabular}{lclc}
\hline Groups & Mean LS & \multicolumn{2}{c}{ Std Dev. Sig level } \\
\hline Corona Zone & & & \\
$\quad$ Red & 3.46 & 0.82 & $\mathbf{0 . 2 4 0}$ \\
$\quad$ Orange & 3.40 & 0.58 & \\
$\quad$ Green & 3.27 & 0.7 & \\
Lockdown Job Status & & & \\
$\quad$ Not working & 3.26 & 0.59 & $\mathbf{0 . 5 2 3}$ \\
$\quad$ Working from home & 3.35 & 0.75 & \\
$\quad$ Going to office & 3.39 & 0.76 & \\
Connect with Family & & & \\
$\quad$ With family & 3.29 & 0.71 & $\mathbf{0 . 1 5 4}$ \\
$\quad$ Away from family & 3.45 & 0.63 & \\
$\quad$ Salary Received during Lockdown & & \\
$\quad$ Yes & 3.36 & 0.70 & $\mathbf{0 . 1 7 8}$ \\
$\quad$ No & 3.2 & 0.68 & \\
\hline
\end{tabular}

During the lockdown, 56 percent of the respondents were working from home and 82 percent were connected with their family. Nguyen et al. (2015) claim that sound relations will have an impact on LS. Studies have also found that if individuals are surrounded by relations, then they have more chances to share their issues, feelings and thoughts (Tayler et al. 2001; Powdthavee 2008). This contributes to life satisfaction. Vautero (2020) found that family support has an impact on life satisfaction. As most of the respondents were with their family they might have received the support from their families and hence LS is the same across the board.

\section{CONCLUSION}

COVID-19 is ravaging across the world and has touched the lives of every single individual in one way or the other. It had also forced people to change their lifestyle and move to a new 'normal'. In this context, this study examined the life satisfaction of respondents in Tamilnadu and found that 70 percent of them were satisfied with their lives. Marital satisfaction and physical health were found to be associated with LS. The study has also reiterated the statement "Health is Wealth" by showing the association between physical health, mental health, marital satisfaction and life satisfaction. The study replicated some of the findings with respect to age and gender, as brought out by previous studies in South Asian Context. In conclusion, the impact of COVID-19 is to be felt even in the coming days and this study is a fresh breather as it found that despite the ravaging pandemic, most of the respondents were found to be satisfied with their lives.

\section{RECOMMENDATIONS}

As this is the first occurrence of a pandemic of this magnitude, this study can be replicated on a large sample to understand the interplay between the variables of interest. As the impact of the pandemic is felt world over, cross-cultural studies can also be conducted to enhance understanding. Life satisfaction is a key aspect of the life of individuals and it affects the personal and professional lives of individuals. Hence a detailed study in this regard is warranted.

\section{REFERENCES}

Ackerman CE 2020. Life Satisfaction Theory and 4 Contributing Factors. From <https://positivepsychology. com/life-satisfaction/> (Retrieved on 22 May 2020).

Amati V, Meggiolaro S, Rivellini G, Zaccarin S 2018. Social relations and life satisfaction: The role of friends. Genus, 74

Appleton S, Song L 2008. Life satisfaction in urban China: Components and determinants. World Development, 36(11): 2325-2340.

Balachandran M, Raakhee AS, Sam Sananda Raj H 2007. Life satisfaction and alienation of elderly males and females. J Indian Academy Appl Psychol, 33(2): 157-160.

Ball R, Chernova K 2008. Absolute income, relative income, and happiness. Social Indicators Research, 88(3): 497-529.

Banjare P, Dwivedi R, Pradhan J 2015. Factors associated with life satisfaction amongst the rural elderly in Odisha, India. Health and Quality of Life Outcomes, 13: 201. doi: 10.1186/s12955-015-0398-y

Bartram D 2020. Age and life satisfaction: Getting control variables under control. Sociology. https://doi.org/ 10.1177/0038038520926871

Bennett KM 2005. Psychological wellbeing in later life: The longitudinal effects of marriage, widowhood and 
marital status change. Int J Geriatr Psychiatry, 20(3): 280-284.

Bilal A Rasool S 2020. Marital satisfaction and satisfaction with life: mediating role of sexual satisfaction in married women. Journal of Psychosexual Health, 2(1): 77-86. https://doi.org/10.1177/26318 318209 12873

Binder M, Coad A 2011. From average Joe's happiness to Miserable Jane and Cheerful John: Using quantile regressions to analyze the full subjective well-being distribution. Journal of Economic Behavior \& Organization, 79(3): 275-290.

Blanchflower DG 2008. Happiness Economics. NBER Reporter: Research Summary Number 2. From <https://www.nber.org/reporter/2008number2/blanchflower. html $>$ (Retrieved on 27 May 2020)

Blanchflower DG, Oswald AJ 2004. Well-being over time in Britain and the USA. Journal of Public Economics, 88: 1359-1386.

Botha F, Booysen F 2013. The relationship between marital status and life satisfaction among South African adults. Acta Academica, 45(2): 150-178.

Cayla.Weebly.Com 2020. India. From <https://incredible-india-cayla.weebly.com/hofstedes-culturaldimensions.html> (Retrieved on 27 May 2020).

Chen W-c 2012. How education enhances happiness: Comparison of mediating factors in four east asian countries. Social Indicators Research, 106(1): 117131.

Clark AE Oswald AJ 1994. Unhappiness and unemployment. The Economic Journal, 104(424): 648-659.

Clark AE, Diener E, Georgellis Y, Lucas RE 2008. Lags and leads in life satisfaction: A test of the baseline hypothesis. The Economic Journal, 118(529): F222F243.

Cun ado J de Gracia F 2012. Does education affect happiness? Evidence for Spain. Social Indicators Research, 108(1): 185-196.

Daraei M,Mohajery A 2013. The impact of socioeconomic status on life satisfaction. Soc Indic Res, 112: 69-81. https://doi.org/10.1007/s11205-012-0040-x

De Vaus D 2001. Research Design in Social Research. UK: Sage Publications.

Deci EL, Ryan EM 2002. Handbook of Self-determination Research. Rochester: University of Rochester Press.

Delhey J 2004. Life Satisfaction in an Enlarged Europe. Luxembourg: Office for Official Publications of the European Communities.

Dolan P, Peasgood T, White M 2008. Do we really know what makes us happy? A review of the economic literature on the factors associated with subjective well-being. Journal of Economic Psychology, 29: 94122.

Easterlin RA 1995. Will raising the incomes of all increase the happiness of all? Journal of Economic Behavior \& Organization, 27(1): 35-47.

Easterlin RA 2003. Explaining Happiness. Proceedings of the National Academy of Sciences, 100: 1117611183.

Ebrahim A, Botha F, Snowball J 2013. Determinants of life satisfaction among race groups in South Africa. Development Southern Africa, 30(2): 168-185.
Ellison CG, Gay DA, Glass TA 1989. Does religious commitment contribute to individual life satisfaction? Social Forces, 68: 100-123.

Eroglu SE, Bozgeyikli H, Calisir V 2009. Life satisfaction depending on socio-economic status and gender among Turkish students. Policy Futures in Education, 7(4): 379-386.

Fernandez-Ballesteros R, Zamarron MD, Ruiz MA 2001. The contribution of sociodemographic and psychosocial factors to life satisfaction. Aging and Society, 21: $25 \mathrm{e} 43$.

Ferring FD, Balducci C, Burholt V, Wenger C, Thissen F, Weber G, Hallberg IR 2004. Life satisfaction of older people in six European countries: findings from the European study on adult well-being. Eur J Ageing, 1: $15-25$.

Frazier P, Arikian N, Benson S, Losoff A, Maurer S 1996. Desire for marriage and life satisfaction among unmarried heterosexual adults. Journal of Social and Personal Relationships, 13(2): 225-239. https:// doi.org/10.1177/0265407596132004

Gove WR, Hughes M, Style CB 1983. Does marriage have positive effects on the psychological well-being of the individual? Journal of Health and Social Behavior, 24(2): 122-131.

Gwozdz W, Sousa-Poza A 2010. Ageing, health and life satisfaction of the oldest old: An analysis for Germany. Social Indicators Research, 97: 397-417.

Hagerty M, Veenhoven R 2003. Wealth and happiness revisited-Growing national income does go with greater happiness. Social Indicators Research, 64(1): $1-27$.

Halpern D 2005. Social Capital. Cambridge: Polity Press.

Helliwell J, Layard R, Sachs J 2011. World Happiness Report. The Earth Institute: Columbia University.

Hendrick SS 1988. A generic measure of relationship satisfaction. Journal of Marriage and the Family,50: 93-98.

Iwatsuba Y, Derriennlc F, Cassou B, Poitrenaud J 1996. Predictors of Life Satisfaction among retired people in Paris. International Journal of Epidemiology, 25: 160-170.

Kasapoglu F, Yabanigul A 2018. Marital satisfaction and life satisfaction: The mediating effect of spirituality. Spiritual Psychology and Counseling, 3: 177-195. http://dx.doi.org/10.12738/spc.2018.3.2.0048

Kim B, Shin BC 2009. Study on the satisfaction of leisure and life, according to the degree of participation of the swimming club members. Journal of Sport and Leisure Studies, 38: 1295-1303.

Kim K 2012. The relationship of social support, leisure satisfaction, psychological happiness and participatory behavior of the elderly participation in swimming activities. Korean Journal of Physical Education, 51: 53-62.

Krishnaveni VD, Harish V, Mary Jeyanthi P, Mansurali A 2020. COVID-19: Impact on Indian agriculture. International Journal of Psychosocial Rehabilitation, 24(5): 3465-3472.

Lee B, Oh D 2013. The effects of health perception on living health belief, living satisfaction and wellbeingoriented activities according to swimming participa-

J Hum Ecol, 71(1-3): 127-138 (2020) 
tion with middle-aged women. Journal of Exercise Rehabilitation, 9(3): 381-388.

Lombardo P, Jones W, Wang L, Shen X, Goldner EM 2018. The fundamental association between mental health and life satisfaction: Results from successive waves of a Canadian national survey. BMC Public Health, 18(1): 342. doi:10.1186/s12889-018-5235$\mathrm{x}$.

Mafini C 2017economic factors and life satisfaction: trends from South African communities. ActaUniversitatisDanubius. OEconomica, Danubius University of Galati, 13(3): 155-168.

Mahadea D, Rawat T 2008. Economic growth, income and happiness: an exploratory study. South African Journal of Economics, 76: 276-290.

Maheswaran T,Ranjit L 2013. A study on life satisfaction among elderly people. Res $J$ Sociology, 1: 1-8.

Mansurali A, Deepa R, Harish V 2020. Impact of COVID-19 on marital satisfaction - Insights from South India. Journal of Psychosocial Rehabilitation, 24(5): 6592-6618.

Margolis S, Schwitzgebel E, Ozer DJ, Lyubomirsky S 2019. A new measure of life satisfaction: The Riverside Life Satisfaction Scale. J Pers Assess, 101(6):621630. doi:10.1080/00223891.2018.1464457

Marpady P, Jyothi PS, Singhe MS 2012. Social support network and life satisfaction among elders in Mangalore Taluk: An implication for social work intervention. Elixir Soc Sci, 48: 9457-9460.

Møller V 2007. Satisfied and dissatisfied South Africans: results from the general household survey in international comparison. Social Indicators Research, 81: 389-415.

Myers DG, Diener E 1996. The pursuit of happiness. Scientific American, 54-56.

Myers DG2000. The funds, friends, and faith of happy people. American Psychologist, 55(1): 56-67.

Nettle D 2005. Socio-economic Status and Subjective Well-being. From <http://worlddatabaseofhappiness. eur.nl/hap_bib/freetexts/nettle_d_2005.pdf > (Retrieved on 22 May 2020).

Ngoo YT, Tey NP, Tan EC 2015. Determinants of life satisfaction in Asia. Soc Indic Res, 124: 141-156. https://doi.org/10.1007/s11205-014-0772-x

Nguyen AW, Chatters LM, Taylor RJ, Mouzon DM 2015. Social support from family and friends and subjective well-being of older African Americans. Journal of Happiness Studies. https://doi.org/10.1007/s10902015-9626-8.

O’Neill M 2010. Cultural attendance and public mental health - from research to practice. Journal of Public Mental Health, 9(4): 22-29.

Ortiz-Ospina E, Roser M 2020. Happiness and Life Satisfaction. From <https://ourworldindata.org/happinessand-life-satisfaction> (Retrieved on 22 May 2020).

Oshio T, Kobayashi M 2010. Income inequality, perceived happiness, and self-rated health: Evidence from nationwide surveys in Japan. Social Science and Medicine, 70: 1358-1366.

Özer BU, Sackes M 2011. Effects of academic procrastination on college students' life satisfaction. Procedia Social and Behavioral Sciences, 12: 512-519.
Peiro A 2006. Happiness, satisfaction and socio-economic conditions: Some international evidence. The Journal of Socio-Economics, 35: 348-365.

Posel DR, Casale DM 2011. Relative standing and subjective well-being in South Africa: The role of perceptions, expectations and income mobility. Social Indicators Research, 104: 195-223.

Powdthavee N 2008. Putting a price tag on friends, relatives, and neighbours: Using surveys of life satisfaction to value social relationships. The Journal of Socio-Economics, 37(4): 1459-1480.

Prince M, Patel V, Saxena S, Maj M, Maselko J, Phillips MR et al. 2007. No health without mental health. Lancet. 370: 859-877.

Ra J, An S, Rhee KJ 2013. The relationship between psychosocial effects and life satisfaction of the Korean elderly: Moderating and mediating effects of leisure activity. $J A H, 2(11)$ : 21-35.

Reyes MF, Satorres E, Meléndez JC 2020. Resilience and socioeconomic status as predictors of life satisfaction and psychological well-being in Colombian older adults. Journal of Applied Gerontology, 39(3): 269276. https://doi.org/10.1177/0733464819867554

Salinas-Jiménez MM, Artés JY, Salinas-Jiménez J 2011. Education as a positional good: A life satisfaction approach. Social Indicators Research, 103(3): 409426.

Schimmel J 2009. Development as happiness: The subjective perception of happiness and UNDP's analysis of poverty, wealth and development. Journal of Happiness Studies, 10(1): 93-111.

Schoenborn CA 2004. Marital Status and Health, United States 1999-2002. US Department of Health and Human Services, Centers for Disease Control and Prevention, National Center for Health Statistics, USA.

Sener A, Oztop H, Dogan N, Guvev S 2008. Family, close relatives, friends: life satisfaction among older people. Educ Gerontol, 34: 890-906.

Sotgiu I, Galati D, Manzano M, Rognoni E 2011. Happiness components and their attainment in old age: A cross-cultural comparison between Italy and Cuba. Journal of Happiness Studies, 12(3): 353-371.

Subasi F, Hayran O 2005. Evaluation of life satisfaction index of the elderly people living in nursing homes. Arch Gerontol Geriat, 41: 23-29.

Suh S, Choi H, Lee C, Cha M, Jo I 2012. Association between knowledge and attitude about aging and life satisfaction among older Koreans. Asian Nurs Res, 6(3): 96-101.

Sukamolson S 2007. Fundamentals of Quantitative Research. Thailand: Language Institute Chulalongkorn University.

Taylor RJ, Chatters LM, Hardison CB, Riley A 2001. Informal social support networks and subjective wellbeing among African Americans. Journal of Black Psychology, 27(4): 439-463.

Tiliouine $\mathrm{H}$ 2009. Health and subjective wellbeing in Algeria: A developing country in transition. Applied Research in Quality of Life, 4(2): 223-238.

Vautero J, Taveira MdoC, Silva AD, Fouad NA 2020. Family influence on academic and life satisfaction: A

J Hum Ecol, 71(1-3): 127-138 (2020) 
social cognitive perspective. Journal of Career Development. https://doi.org/10.1177/08948453 20902270

Veenhoven R 1996. The study of life satisfaction. In: WE Saris, R Veenhoven, AC Scherpenzeel, B Bunting (Eds.): A Comparative Study of Satisfaction with Life in Europe, Budapest: EOtvOs University Press, pp. $11-48$.

Veenhoven R 2009. How do we assess how happy we are? In: AK Dutt, B Radcliff (Eds.): Happiness, Eco- nomics and Politics: Towards a Multi-disciplinary Approach.Cheltenham: Edward Elgar Publishers, Chapter 3, pp. 45-69.

Vinson T, Ericson M 2012. Life Satisfaction and Happiness. Richmond: Jesuit Social Services.

Yul DD, Gaibie F 2011. Quality of life in post-apartheid South Africa. Politikon: South African Journal of Political Studies, 38(2): 231-256.

Paper received for publication in May, 2020

Paper accepted for publication in June, 2020

J Hum Ecol, 71(1-3): 127-138 (2020) 